Abstracta Iranica Abstracta Iranica

Revue bibliographique pour le domaine irano-aryen

Volume 42-43 | 2021

Comptes rendus des publications de 2019-2020

\title{
Saeedeh Shahnahpur. Writing War in Contemporary Iran: The Case of Esmā’il Fasih's Zemestān-e 62
}

Julie Duvigneau

\section{OpenEdition}

1 Journals

\section{Édition électronique}

URL : https://journals.openedition.org/abstractairanica/54379

DOI : 10.4000/abstractairanica.54379

ISSN : 1961-960X

Éditeur :

CNRS (UMR 7528 Mondes iraniens et indiens), Éditions de l'IFRI

Référence électronique

Julie Duvigneau, « Saeedeh Shahnahpur. Writing War in Contemporary Iran: The Case of Esmāil Fasih's Zemestān-e 62 », Abstracta Iranica [En ligne], Volume 42-43 | 2021, document 4, mis en ligne le 30 décembre 2021, consulté le 13 décembre 2022. URL : http://journals.openedition.org/ abstractairanica/54379; DOI : https://doi.org/10.4000/abstractairanica.54379

Ce document a été généré automatiquement le 13 décembre 2022.

Tous droits réservés 


\title{
Saeedeh Shahnahpur. Writing War in Contemporary Iran: The Case of Esmā'il Fasih's Zemestān-e 62
}

\author{
Julie Duvigneau
}

\section{RÉFÉRENCE}

Saeedeh Shahnahpur. Writing War in Contemporary Iran: The Case of Esmä'il Fasih's

Zemestān-e 62. New York: Peter Lang, 2019, 177 P.

1 S. Shahnahpur offre ici la première monographie consacrée à Esmā’il Fasih en anglais. Après une introduction très claire sur le contexte d'écriture d'Hiver 83 , le livre consacre un premier chapitre parfois un peu descriptif à la vie et de l'œuvre de l'auteur, en distinguant entre les textes antérieurs à la révolution et ceux écrits après. Ces derniers sont replacés dans le contexte des romans de guerre iraniens. La partie consacrée à la représentation des femmes martyrs est très intéressante.

Le deuxième chapitre se concentre sur Hiver 83 et fait une analyse de la rhétorique de la guerre telle qu'elle se développe dans ce livre. L'étude approfondie de ce roman central dans la littérature persane contemporaine permet d'éclairer les bouleversements socio-politiques à l'œuvre pendant la période de la guerre Iran-Irak et montre à quel point la position adoptée par Fasih est éloignée de celle de la littérature de la Défense sacrée. L'A. montre que Fasih n'était pas un écrivain de propagande, mais qu'il a interrogé les codes de cette nouvelle littérature.

Le troisième chapitre propose une typologie des personnages du roman selon leur classe sociale et le quatrième s'intéresse au cadre spatio-temporel du roman.

On peut ne pas suivre certaines positions de l'A., notamment lorsqu'elle affirme que le roman « promeut un message patriotique à travers son personnage principal » (p. 10), mais ce livre ouvre un espace à l'étude approfondie de la position originale de Fasih sur 
ce sujet ainsi que dans la littérature contemporaine iranienne. Il est à espérer que d'autres études sur Fasih suivront ce travail pionnier.

\section{AUTEURS}

JULIE DUVIGNEAU

INaLCO, CeRMI, Paris 